\title{
Construction of Teacher Science and Research Performance Evaluation System in Public Security Colleges
}

\author{
Jianping Si and Liqu Song
}

Publicity Department of National Police University of China, Liaoning, Shenyang, 110035;

Personnel Department and of National Police University of China, Liaoning, Shenyang, 110035

\begin{abstract}
Teachers in public security colleges are the main force in carrying out scientific research activities. In order to improve the enthusiasm and quality of scientific research in public security colleges, we need to design a scientific and reasonable teacher science and research performance evaluation system. Performance evaluation represents the development direction of social organization management. Therefore, to construct a scientific, impartial and reasonable teacher science and research performance evaluation system has great significance in improving scientific research ability of teachers and the value judgment of the input and output of scientific research activities. Improving teacher science and research performance evaluation system and constructing teacher science and research performance evaluation mechanism are conducive to the scientific research management, the statistical of research workload, and the improvement of the overall academic atmosphere of colleges.
\end{abstract}

Keywords: Public security institutions; Teachers; Research; Performance evaluation; System

\section{公安院校教师科研绩效评价体系的构建}

\author{
司建平宋立渠 \\ (中国刑事警察学院宣传处, 辽宁 沈阳 110035; 中国刑事警察学院组织人事处, 辽宁 沈阳 110035 ) \\ 摘要: 公安院校教师是开展科研活动的主力军, 为提高其科研积极性和公安院校科研质量, 需要设计科学合理的公安院 \\ 校教师科研绩效评价制度。绩效评价代表着社会组织管理的发展方向, 构建一个科学、公正、合理的公安院校教师科研绩效 \\ 评价体系, 对公安院校教师科研能力的提高以及对在科研活动中投入、产出情况进行价值判断, 具有重要的现实意义。完善 \\ 教师科研绩效评价制度, 构建公安院校教师科研绩效评价机制, 有利于开展科研管理, 统计科研工作量, 提高学校的整体学 \\ 术氛围。
}

关键词: 公安院校; 教师; 科研; 绩效评价; 体系

\section{1 绩效评价在科研管理中的作用}

绩效评价是 20 世纪西方较为成功和普及的管理方法, 代表着社会组织管理的发展方向。它首先应用 于企业, 随着院校教育改革的深入, 绩效管理与考评逐渐被引入到院校管理中来。

\section{1 有利于科研开展 PDCA 管理}

PDCA 指的是一项成功管理所必需经历的四个阶段：计划阶段 (Plan)、实施阶段 (Do)、检查阶段 (Check) 和处理、改进阶段 (Act), 四个阶段循环往复, 呈螺旋式上升。对科研工作进行绩效评价主要是进行检查 阶段的工作, 考评的目的并不是以公安此作为聘任或奖惩的主要依据, 而是为了找出科研工作中的问题与 差距, 从而便于进行 PDCA 循环管理的改进阶段工作, 并从整体上提高公安院校的科研工作水平以及学校 的科研创新能力。

\section{2 有利于规范地统计科研工作量}

科研管理工作的绩效评价是抽象的, 因此多从 “绩效” 的角度进行定量的评价。这就需要有相对完善 
和全面的科研工作效率和效果统计数据, 如科研项目总量, 已鉴定科研项目总量, 科技成果获奖数, 发表 论文、专著数目, 当年拨入、支出的科研经费等。因此, 对科研工作进行绩效评价, 有利于规范相应的资 料统计程序。

\section{3 有利于提高学校的整体学术氛围}

院校是一个特殊的社会组织, 教学和科研工作都是其工作重点。离开了科研, 发展就没有了依据, 失 去了创新的源泉。因此, 对学校科研工作进行绩效评价, 一方面能及时地发现问题进行整改, 另一方面, 根据考评的结果相应地对考评结果优秀的部门和个人进行奖励, 有利于形成院校良好的学术氛围, 于无形 中推动科研管理工作的进展。

\section{2 绩效评价指标的确定原则}

\section{1 鼓励创新和分类评价原则}

科研绩效不但取决于公安院校教师所发表成果的数量, 而且取决于他所发表成果的质量。因此, 在科 研绩效评价中要坚持 “计量有据, 鼓励创新” 的原则。分类评价主要指在学校内部由于学科特点不同、研 究类型不同, 在对评价过程中区别对待, 促进基础研究和应用研究、开发研究均衡发展。

\section{2 目的性和导向性原则}

目的性就是结合国家当前的科技政策和学校发展目标，有目的地引导教师紧紧围绕国家和学校的发展 目标进行科研活动。通过科研绩效评价, 激发科技人员的积极性, 促进高校科研活动的健康发展。导向性 即是通过一些指标量化过程中权重的变化, 体现学校管理层对教职工科研活动的期望, 引导科技工作向纵 深发展, 导向性原则是选定考核指标、确定有关权重大小的主要依据。在教师科研绩效评价指标体系中, 指标的设立能够全面合理地反映教师的科研工作, 指标体系应由粗到细, 采取逐步细化的渐进方式, 并且 具有可操作性。

\section{3 系统性与可操作性}

指标体系是实施定量评价的核心，科研绩效的表现越是形式各异，指标体系设计越需要透过现象将其 梳理为一个有机的整体, 使各类科研成果都能够在科研绩效的大系统内被量化评价, 指标体系要无所不包, 各有对应，具有简捷的可操作性。

\section{3 公安院校教师科研绩效评价存在的问题}

\section{1 科研绩效评价结果对教师个人发展影响过大}

大学教师的社会责任主要包括教学、科研和社会服务三方面, 但我国目前大部分公安院校都普遍存在 片面看重科研绩效评价结果的问题, 有的公安院校甚至把科研绩效评价作为衡量院校教师成就的唯一指 标。这不仅异化了科研绩效评价的初衷, 而且还直接影响到公安院校教师投身于教学的积极性。

\section{2 “重量轻质”思维渗透到科研绩效评价各环节}

公安院校科研绩效评价可以简单地分为“同行评议”和 “量化考核”两种方式。前者是同行专家依据 专业学术知识和专业精神对科研成果的质量和意义进行综合判断, 是一种质化（定性）评价方式, 而量化 考核更多的是依据量化计分系统对科研成果进行定量计算, 得出绩效水平。从形式上来说, 同行评价在我 国公安院校教师科研绩效评价实践中得到了较为广泛的应用。如当前国内几乎所有重要的课题立项、结项 评审都采用同伴评审方式, 绝大部分大学在教师职称评定时也非常倚重同行评审。但问题的关键不是有没 
有同行评议，而是怎么进行同行评价以及同行评价在整个评价的权重。当前，尽管有同行评议，但量化考 核的思路依然占据统治性地位。这可以证之于两方面: 第一, 许多专家在进行同样评议时, 仍沿采用量化 思路。如专家在对两位不同候选人的材料进行评选时, 经常习惯性地给其中一位在量上有更多成果的候选 人以更高评价。在这种情况下，虽然有同行评议，但其实质仍然是量化考核，只不过考核的主体变成了同 行而已。第二, 即使在一些时候, 专家同行评议采取质化评价方式, 但这种评价的结果会变成另外一个数 字 (如获得了一项自然科学基金)。在这种情况下, 同行评议变成了一种手段, 真正重要的还是量化考核 的结果。

\section{3 量化考核失之于简单和表面}

从理论上说，同行评价与量化考核并无绝对高下之分。量化考核如果能够运用得好，其优势非常明显。 但问题在于我们没有把量化考核用好, 使之流于简单和表面。我们知道, 根据某项研究成果的转载次数、 影响力、引用率、社会效益进行评价, 这也是一种量化考核方式法, 而且这种考核从某个角度上来说是更 多地在鼓励生产高质量的科研成果。但遗憾的是, 在我们大部分院校科研绩效考核机制中, 更多的是对那 些表面的、低层次的数据进行统计、考核, 如发表论文的篇数, 所发表刊物的级别和影响因子, 国家级课 题立项的次数等等。量化考核本来是要研究如何把抽象的科研绩效具体化为可以测量的指标数据, 其过程 是复杂的。但我们却把它变得过于简单和表面, 甚至简单到所有人都可以来评价大学教授的科研绩效和能 力。

\section{4 构建公安院校教师科研绩效评价的措施}

\section{1 以提高科研绩效为目标, 采用定性评价与定量评价相结合的办法}

目前, 我国公安院校在科研评价方法上主要有同行评议、成果计数和文献计量等方法。同行专家最能 了解研究工作的水平和价值, 但同行评议在实际操作过程中不可避免地存在着评价主观性太强等局限性。 而成果计数、文献计量等定量评价方法在提高评价效率、避免评价过程中某些人为因素的干扰等方面具有 重要的作用。公安院校进行教师科研评价时应各有侧重, 采用定性与定量相结合的方法, 既重数量又重质 量。

\section{2 切实推进同行评议制度}

无论制度设计本身，还是在公安院校实施的具体实践，同行评议并不是没有缺点，但我们应该请晰地 看到, 从学术研究的内在逻辑上来说, 同行评议是一个相对更为合理的科研绩效评价机制。在推进同行评 议过程中, 必然会遇到各种各样的问题, 但我们不能因为这些问题的存在而放弃努力。在当前, 同行评议 制度的推行不可避免地会遇到人情关系等因素的影响, 许多人也因此认为同行评议还不如简单的量化考 核。但我们要认识到, 这是我们发展过程中的一个必然成本。只要我们持续地提供机会, 允许试误, 并积 极从错误中总结经验, 那么大家会逐渐地适应、理解这种评价方式的。毕竟, 大部分学者从理念上都能认 同同行评价的价值所在, 只是作为一项新生事物, 大家还没有建立起相应的思维习惯。如果我们因为暂时 出现了一些困难, 就退回去求助于简单的量化考核, 是解决不了问题的。而且, 对当前的困难和争议, 许 多人实际上是持一种观望态度, 想试探一下管理者推进同行评议的决心，一旦他们觉得这是一个必然方向 之后, 他们中的许多人会成为改革的积极推动者。 
4.3 完善科研激励机制, 保证评价工作的公开、公正

在公安院校的科研绩效考评时, 要改变目前 “一刀切” 的现状, 充分尊重、承认教师的科研劳动成果, 体现实事求是、按劳分配原则, 从物质和精神角度使教师的劳动得到应有的报酬, 使其劳动价值为学校和 社会所认可。要有意识地引导教师科研向着学校的中长期目标发展, 实现目标管理, 从而起到提高科研水 平，创造办学特色，促成学科优势的形成。此外，在科研业绩核定和管理工作中，应及时面向全校师生和 管理部门发布科研业绩统计信息和评价结果, 避免因不公正的评价过程与不公正地对待评价结果所带来的 负面影响, 力求做到公平与公正, 有助于科研业绩评价工作的规范化、科学化、高效化, 有助于公开透明 评价机制的形成，有助于营造良好的学术环境。

\section{致谢:}

基金支持: 本文系辽宁省教育科学 “十三五” 规划 2016 年度立项课题《公安院校教师科研绩效评价 体系研究》, 课题编号: JG16DB487 的阶段性研究成果。

Fund support: This paper is the initial result of Research on Teacher Science and Research Performance Evaluation System in Public Security Colleges, which is 2016's annual project judging of the 13th Five-Year plan of educational science of Liaoning province, whose project number is: JG16DB487.

\section{参考文献:}

[1] 张喜爱. 高校科研业绩评价办法研究 $[J]$. 科技管理研究，2007（9）.

[2] 付广发. 高校科研工作绩效考评探究 $[J]$ 。科技管理研究，2006（10）：57-59.

[3] 李继怀，金永龙．机制创新：高校科研绩效评价指标体系的构建［J]．科技管理研究，2009（6)：35-38.

[4] 陈长喜，卢秉福. 高等学校教师激励机制研究 $[J]$. 黑龙江高教研究，2011，(1).

[5] 卢秉福，霍丽华，陈长喜. 高校教师科研绩效评价体系研究 $[J]$. 科技与管理，2010，(4).

[6] 王光彦，李元元，邱学青等．高校教师绩效评价指标体系的实证研究与思考 [J]. 中国高教研究，2008 (02).

[7］史万兵，杨慧．高等学校教师科研绩效评价方法研究 [J].高教探索，2014（6)：112-117.

[8] Robert Cannon, David Newble. A HandbookFor Teachers in Universities and Colleges: A Guide toImproving Teaching Methods [M]. 2000: 225.

[9] William D. Wolansky. A Multiple Approach toFaculty Evaluation [J]. Education, 2001, (1):81 - 96.

[10］叶继元. 学术评价何以必要与可能 [N] . 光明日报, 2010-08-03.

\section{References:}

[1] Zhang Xi'ai. Study on Performance Evaluation Methods of Scientific Research in Colleges and Universities [J].Science and Technology Management Research, 2007(9).

[2] Fu Guangfa. Research on Performance Evaluation of Scientific Research in Colleges and Universities [J].Science and Technology Management Research, 2006(10):57-59.

[3] Li Jihuai,Jin Yonglong. Mechanism Innovation: Construction of Evaluation Index System for Performance of Scientific Research in Colleges and Universities [J].Science and Technology Management Research, 2009(6):35-38.

[4] Chen Changxi, Lu Bingfu. Study on Incentive Mechanisms of Teachers in Colleges and Universities [J].Heilongjiang Researches on Higher Education, 2011, (1).

[5] Lu Bingfu, Huo Lihua, Chen Changxi. Study on Performance Evaluation System of Teachers' 
Scientific Research in Colleges and Universities [J].Technology and Management, 2010, (4).

[6] Wang Guangyan, Li Yuanyuan, Qiu Xueqing, and so on. Empirical Study and Thought of Performance Evaluation System Teachers' Scientific Research in Colleges and Universities [J].China Higher Education Research, 2008(02).

[7] Shi Wanbing, Yang Hui. Study on Performance Evaluation System method of Teachers' Scientific Research in Colleges and Universities [J].Higher Education Exploration, 2014(6):112-117.

[8] Robert Cannon, David Newble. A HandbookFor Teachers in Universities and Colleges: A Guide toImproving Teaching Methods [M]. 2000: 225.

[9] William D. Wolansky. A Multiple Approach toFaculty Evaluation [J]. Education, 2001, (1): 81-96.

[10] Ye Jiyuan. Academic Evaluation, Why to Be Necessary and Possible [N]. Guang Ming Daily, 2010-08-03.

[11]R. .John Casey. Patricia Gentile and Stephen W. Bigger. Teaching Appraisal in Higher Education: anAustralian Perspective [J]. Higher Education, 1997: 459- 482. 